\title{
Alpha-1 Acid Glycoprotein Measurement
}

National Cancer Institute

\section{Source}

National Cancer Institute. Alpha-1 Acid Glycoprotein Measurement. NCI Thesaurus. Code C100429.

The determination of the amount of alpha- 1 acid glycoprotein present in a sample. 